Guyonne LEDUC, Réécritures anglaises au XVIII siècle de l'"égalité des deux sexes » (1673) de François Poulain de la Barre. Du politique au polémique

\title{
Martine Lapied
}

\section{(2) OpenEdition}

\section{Édition électronique}

URL : https://journals.openedition.org/ahrf/12163

DOI : $10.4000 /$ ahrf.12163

ISSN : 1952-403X

Éditeur :

Armand Colin, Société des études robespierristes

\section{Édition imprimée}

Date de publication : 1 septembre 2011

Pagination : 206-207

ISBN : 978-2-200-92700-4

ISSN : 0003-4436

\section{Référence électronique}

Martine Lapied, "Guyonne Leduc, Réécritures anglaises au xvIII" siècle de l'« égalité des deux sexes " (1673) de François Poulain de la Barre. Du politique au polémique », Annales historiques de la Révolution française [En ligne], 365 | Juillet-septembre 2011, mis en ligne le 13 décembre 2011, consulté le 24 avril 2022. URL : http://journals.openedition.org/ahrf/12163 ; DOI : https://doi.org/10.4000/ahrf.12163

Ce document a été généré automatiquement le 24 avril 2022.

Tous droits réservés 


\title{
Guyonne LEDUC, Réécritures anglaises au XVIII siècle de l'" égalité des deux sexes » (1673) de François Poulain de la Barre. Du politique au polémique
}

\author{
Martine Lapied
}

\section{RÉFÉRENCE}

Guyonne LEDUC, Réécritures anglaises au XVIII ${ }^{\mathrm{e}}$ siècle de l'« égalité des deux sexes » (1673) de François Poulain de la Barre. Du politique au polémique, Paris, L'Harmattan, 2010, 502 p. ISBN : 978-2-296-11263-6, $43 €$.

1 Guyonne Leduc, agrégée d'anglais, professeur à l'Université Charles de Gaulle (Lille 3), directrice de la collection Des idées et des femmes, présente ici une recherche très fouillée sur des brochures "pré-féministes » anglaises du XVIII siècle. Il s'agit d'une étude très précise de ces textes, avec un appareil critique développé sur les auteurs, les œuvres dans leurs différentes éditions, comparées aux écrits de Poulain et à leurs traductions.

2 Le traité de Poulain de la Barre présente l'inégalité entre hommes et femmes comme la marque d'un préjugé dont il veut montrer le non-sens par une analyse cartésienne. Les pamphlets de Sophia sont des brochures anonymes, la première date de novembre 1739 , la seconde, en 1740 , est une réponse à un contradicteur dont le texte date de décembre 1739.

On peut noter l'importance du sous-titre: du politique au polémique qui montre l'évolution d'une pensée philosophique et politique chez Poulain à une volonté polémique, dans ce que Guyonne Leduc désigne comme le pré-féminisme anglais du $\mathrm{XVIII}^{\mathrm{e}}$ siècle qui veut établir l'égalité des âmes et de la raison sans d'ailleurs dénoncer comme Poulain les différences dans les rôles respectifs des hommes et des femmes. 
4 La première partie présente les textes et les contextes. La question de l'accueil relativement indifférent de l'œuvre de Poulain au moment de sa parution est abordée. Néanmoins, on doit remarquer que, si ses ouvrages sont peu évoqués dans d'autres écrits, de nombreuses traductions et éditions ont vu le jour. Le traité de l'égalité paru en 1673 est traduit dès 1677 ; en 1790, l'édition française est diffusée en Angleterre.

C'est dans les années 1740 que les idées de Poulain ressurgissent de façon anonyme par le biais de trois brochures anonymes, dans un contexte de regain de la querelle des femmes. Les idées de Poulain reviendront en France au XVIII ${ }^{\mathrm{e}}$ siècle par le biais de la Grande-Bretagne.

6 Pour Poulain, l'esprit n'a pas de sexe et il attribue un rôle primordial aux conditions matérielles et à l'éducation dans les différences créées par la société entre les hommes et les femmes. À partir d'une analyse cartésienne, dans une démarche sociologique, historique et matérialiste de lutte contre les préjugés, il établit les bases d'une justification philosophique au pré-féminisme. Au tournant du XVII ${ }^{\mathrm{e}}$ et du $\mathrm{XVIII}^{\mathrm{e}}$ siècle anglais, l'éducation des femmes reconnues capables de raison est au centre des préoccupations de ce courant. Les idées de Poulain ressurgissent en 1739 dans les écrits de « Sophia ».

7 La deuxième partie se livre à une analyse comparative. Elle montre, très précisément, que Sophia rédigea ses deux brochures avec la traduction de l'ouvrage de Poulain sous les yeux. Le travail de Guyonne Leduc contribue donc à mettre en lumière le rôle historique d'un homme dans l'émancipation des femmes sur le chemin de l'égalité ses sexes.

8 Mais, si elle est plus incisive que Poulain dans les formulations, et veut apprendre aux femmes à avoir confiance en elles, Sophia est moins progressiste dans les idées.

9 La troisième partie étudie les caractérisations essentielles des pré-féminismes de Poulain et de Sophia. Les deux auteurs se fondent sur la raison et Sophia reprend l'idée que la différence des sexes concerne la reproduction de l'espèce et non l'esprit. Néanmoins Sophia ne pense pas par elle-même, elle utilise le raisonnement de Poulain. Par ailleurs, elle se place dans une optique plus militante, plus critique, jusqu'à l'invective, accablant les hommes qui sont à la fois juges et parties, alors que le constat de Poulain dépersonnalise la responsabilité. Dans la controverse, elle a tendance à utiliser le système du catalogue et à penser en termes de supériorité / infériorité plutôt qu'en termes d'égalité. Elle recourt à la polémique où la passion se substitue à l'argumentation.

10 Poulain veut instruire les femmes pour les libérer et leur permettre l'accession à toutes les fonctions y compris publiques. L'instruction qui permettra l'abandon des préjugés sera source de progrès et de bonheur. Pour Poulain, la soumission des femmes correspond à celle de la société civile. Sa dénonciation de l'injustice faite aux femmes est solidaire de celle de toute l'organisation de la société et de l'absolutisme. On voit toute la modernité d'un penseur du XVII ${ }^{\mathrm{e}}$ siècle qui, sur certains points, tel l'accès de tous, donc des femmes, à toutes les charges au mérite ne sera même pas égalé au moment de la Révolution française.

11 La dimension subversive de l'égalité naturelle et de la relativité des rangs, l'affirmation du mérite personnel contre le droit de naissance, qui existent chez Poulain, ne sont pas repris par Sophia. La féministe anglaise n'est pas intéressée par la dimension politique d'un traité toujours novateur au XVIII ${ }^{\mathrm{e}}$ siècle. 
12 L'étude très documentée d'Yvonne Leduc constitue un apport important dans le domaine de la filiation des idées et de la question des transferts culturels. 